\title{
Hybrid bioceramics with metals and polymers for better biomaterials
}

\author{
T KAMEYAMA \\ Bioceramics Laboratory, National Industrial Research Institute of Nagoya, 1-1 Hirate-cho, Kita, \\ Nagoya 462-8510, Japan
}

\begin{abstract}
The number of people needing artificial bones and teeth will rapidly increase in the world. Hydroxyapatite (HAp) is known to be a suitable ceramic owing to its biological afrinity. However, its use in artificial joints and dental roots is difficult due to its poor mechanical properties. $A$ new method to implant HAp granules into superplastic titanium alloy has been developed. We also succeeded to enhance the biomimetic growth of calcium phosphate on biological fibres (cellulose and chitin) through their surface modification by phosphorylation or silane coupling. This hybrid material may be used as virus filters, artificial trachea etc. The future of hybrid bioceramic materials appears to be promising.
\end{abstract}

Keywords. Hydroxyapatite; biological affinity; titanium alloy; biomimetic growth; polymers; hybrid ceramics.

\section{Hybrid bioceramics with metals}

\subsection{Introduction}

Owing to its biological affinity, hydroxyapatite $\left(\mathrm{Ca}_{10}\left(\mathrm{PO}_{4}\right)_{6}(\mathrm{OH})_{2} \mathrm{HAp}\right)$ can be used in artificial joints and dental roots. However, because of its poor mechanical properties, particularly low fracture toughness, it cannot be used under a heavy load, and therefore its application is limited (Ohgaki and Aoki 1993). If HAp could be coated on to another material, such a composite may be a good biomaterial in terms of its biological affinity and high mechanical strength. The HAp-implanted titanium alloy hybrid materials are expected to be useful as hard biological tissue replacement.

Attempts have been made to produce a composite by coating biocompatible ceramics, such as HAp, with metal. With respect to the production of $\mathrm{HAp} / \mathrm{Ti}$ composites, plasma splay methods have been promising (Geesink et al 1987). However, it has been reported that HAp was easily decomposed by high temperature, and that HAp eventually peeled off in the body after its implantation.

A method has also been reported for the formation of $\mathrm{TiO}_{2}$ alloy, containing calcium oxide and a complex oxide of calcium and titanium, by the implantation of calcium ions into the surface of titanium. However, the thickness of the oxide film used was only approximately $40 \mathrm{~nm}$ (Hanawa et al 1993).

It is known that superplastic titanium alloy ( $\mathrm{Ti}-4.5 \mathrm{Al}-$ $3 \mathrm{~V}-2 \mathrm{Fe}-2 \mathrm{Mo}$ ) is readily formed under a pressure of 17. MPa or less (Ouchi et al 1992), becomes a plastic fluid when heated to $\sim 750-800^{\circ} \mathrm{C}$.

In this study to obtain a biomaterial, which has both biological affinity and high mechanical strength, HAp granules $(32-38 \mu \mathrm{m}$ diameter) were implanted into the substrate of superplastic titanium alloy. The HAp granules were spread over a superplastic titanium alloy substrate and pressed with a plunger to implant them into the substrate (Nonami et al 1998).

\subsection{Experimental}

Titanium alloy, which has the composition Ti-4.5Al3V-2Fe-2Mo (NKK, SP-700, titanium alloy), size $0.49 \mathrm{~mm} \times 15 \mathrm{~mm} \times 15 \mathrm{~mm}$, was used as the substrate. This alloy exhibited superplastic elongation $(2000 \%)$ at $750-800^{\circ} \mathrm{C}$, and thus the press forming tests were performed at $750^{\circ} \mathrm{C}$. HAp powder was granulated using a spray-drier (STK). The granules were heated for $3 \mathrm{~h}$ at 1100 or $1200^{\circ} \mathrm{C}$, and then were shifted to $32-38 \mu \mathrm{m}$. The specimens were manufactured by coating the titanium alloy with silicone grease (Coaning), and the granules adhered to the surface of the alloy. Granules were porous, having a specific pore size of $\sim 1 \mu \mathrm{m}$. HAp granules were implanted by using a hot press into the titanium alloy substrate as follows: specimens were placed between two alumina discs, set in the hot press, and pressed under pressures of $0.38-17 \mathrm{MPa}$ for $10-180 \mathrm{~min}$, at $750^{\circ} \mathrm{C}$ under $0.13 \mathrm{~Pa}$ atmosphere, as shown in figure 1 .

\subsection{Results and discussion}

Granules did not show deformation owing to their uniform implantation into every specimen. The joint area of the substrate adhered closely to the granules, and the surface of the titanium alloy showed a metallic gloss. No change was observed.

Figure 2 shows scanning electron micrographs of the specimens which were pressed under $0.38 \mathrm{MPa}$ at $750^{\circ} \mathrm{C}$ 
for $60 \mathrm{~min}$. After $10 \mathrm{~min}$ implantation, the implantation ratio was $-20 \%$ and some granules were not on the substrate. After $60 \mathrm{~min}$ implantation, the implantation ratio was $100 \%$, but the upper areas of granules were exposed. The titanium alloy near the granules was deformed by the implantation, and deep hollows were seen.

Figure 3 shows scanning electron micrographs of the specimens which were pressed under $17 \mathrm{MPa}$ at $750^{\circ} \mathrm{C}$ for $10 \mathrm{~min}$. The implantation ratio was $100 \%$. The substrate which was directly in contact with the alumina plunger is clearly evident. Only the topmost part of the granules was exposed, the remainder being substrate. With increasing implantation pressure, the contact area between granules and substrate spread. Scanning electron micrographs indicated that the hollows of the substrate around the granules was smaller than for the specimen implanted under a pressure of $0.38 \mathrm{MPa}$.

These facts clarify that the implantation process of a granule is divided into the following two steps: (i) the granules are implanted to a depth corresponding to the diameter with a small stress, and (ii) the complete specimen is produced as the titanium alloy moves over the upper part of the granules which are then firmly stuck in the substrate.

Figure 4 is an electron probe microanalysis (EPMA) spectral diagram showing the change of composition across the interface of the HAp granule and the titanium alloy. While titanium, aluminium and iron diffused into the granule; calcium, oxygen and phosphorous diffused into the titanium alloy. Silicon is present at the interface. The thickness of the interface was about $1 \mu \mathrm{m}$. Silicon, which was included in the silicon grease, diffused, and probably $\mathrm{SiO}_{2}$ was formed. Thus, the granules get chemically combined with the alloy.

\subsection{Conclusions}

To obtain biomaterial, that has both biological affinity and high mechanical strength, HAp granules were implanted into the surface of superplastic titanium alloy.

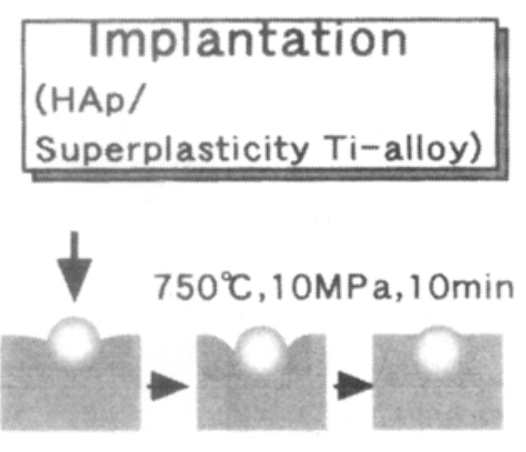

Figure 1. Implantation process.
The HAp granules (32-38 $\mu \mathrm{m}$ diameter) were spread over a superplastic titanium alloy substrate and pressed to implant them into the substrate. The granules were implanted at $750^{\circ} \mathrm{C}, 0.38 \mathrm{MPa}$ for $1 \mathrm{~h}$; and the implantation ratio was $100 \%$, but the upper areas of the granules were exposed. The titanium alloy near the granules was
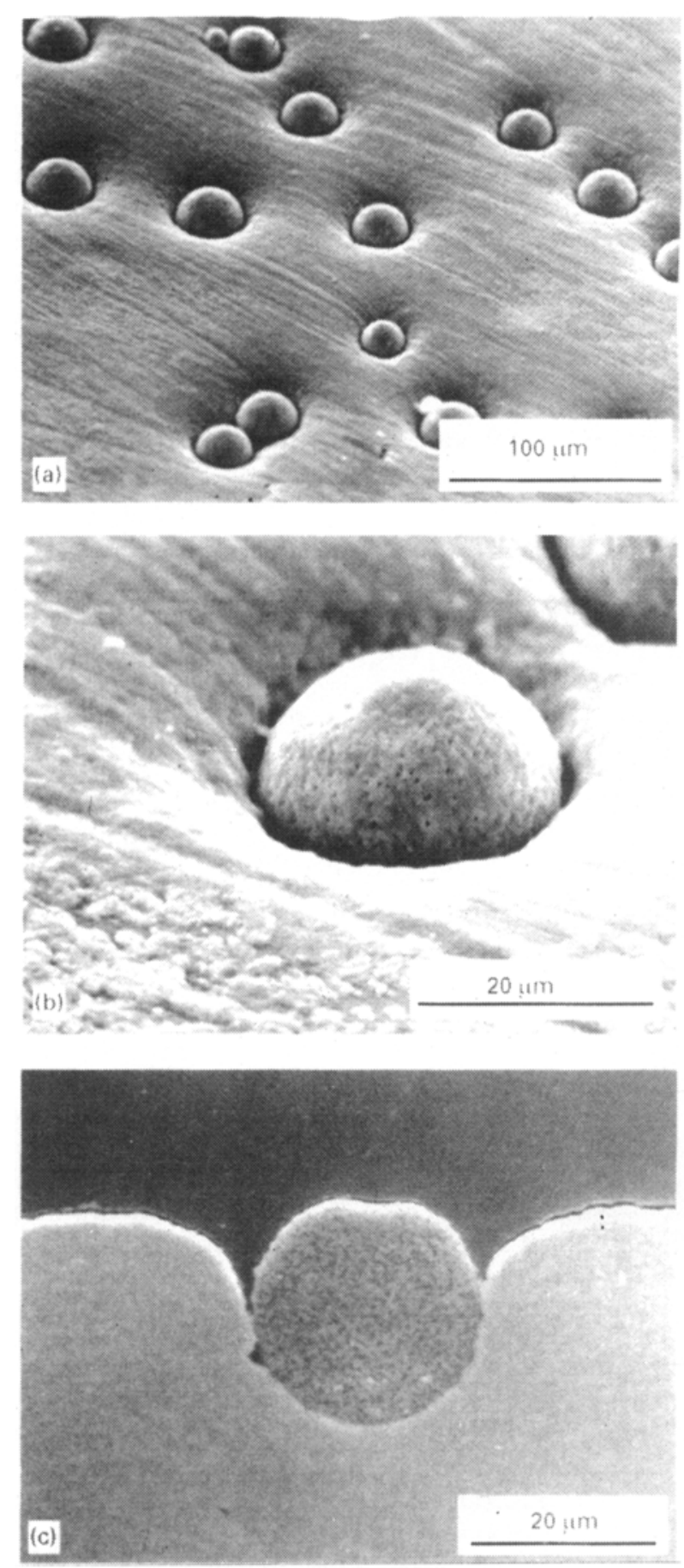

Figure 2. Scanning electron micrographs of specimens with HAp granules implanted into titanium alloy at $750^{\circ} \mathrm{C}$ for 60 $\min$ at $0.38 \mathrm{MPa}$ : (a,b) surface and (c) cross-section. 
deformed by implantation and showed deep hollows. Under a pressure of $17 \mathrm{MPa}$, the implantation ratio was $100 \%$. Only the topmost part of the granules was exposed, and the granules were firmly stuck in the substrate. The granules were finally enclosed in the titanium alloy and
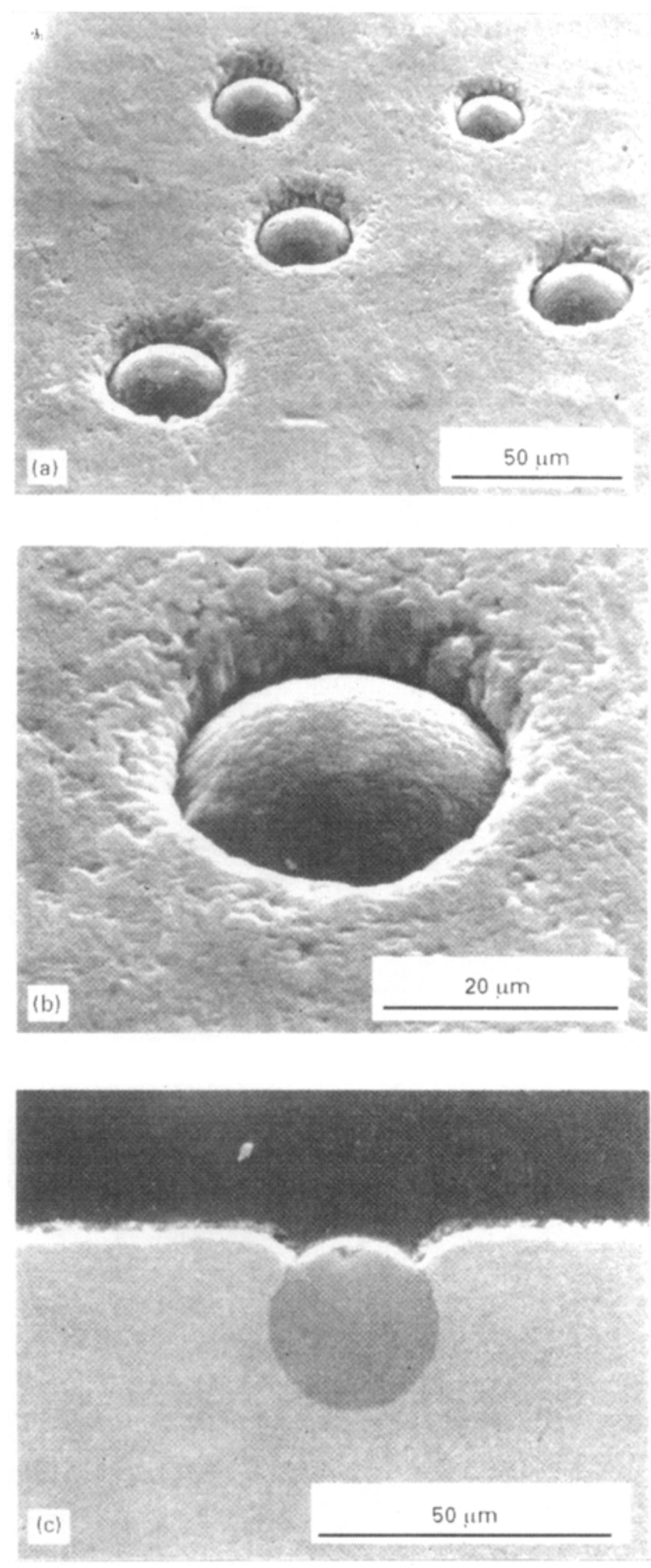

Figure 3. Scanning electron micrographs of specimens with HAp granules implanted into titanium alloy at $750^{\circ} \mathrm{C}$ for 10 min at $17 \mathrm{MPa}$ : (a, b) surface and (c) cross-section. a reaction layer formed at the interface between the HAp granule and the titanium alloy. Thus, the HAp-implanted titanium alloy composites can bc used as biomaterials, for example in artificial bones and dental roots (figure 5) and might not require replacement.

\section{Hybrid bioceramics with polymers}

\subsection{Introduction}

Recent biomimetic studies concerned with the stimulation of calcium phosphate growth on suitably designed substrates have become an extremely important part of biomaterials research due to the insights such investigation can give into the natural deposition of bone-like materials in the body. The introduction of phosphorus-containing

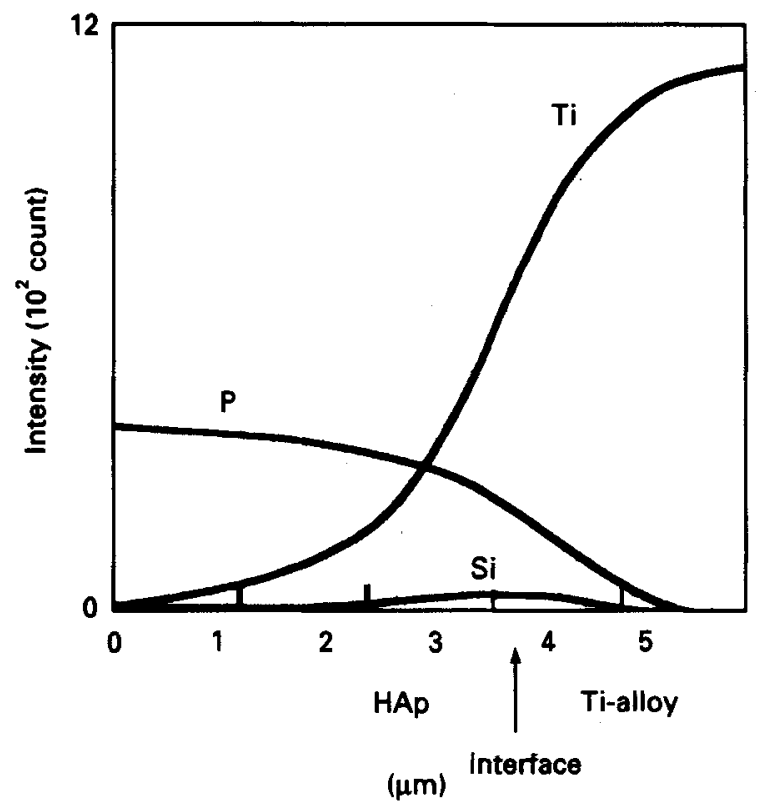

Figure 4. EPMA line profiles of the interface between the HAp granule and the titanium alloy.
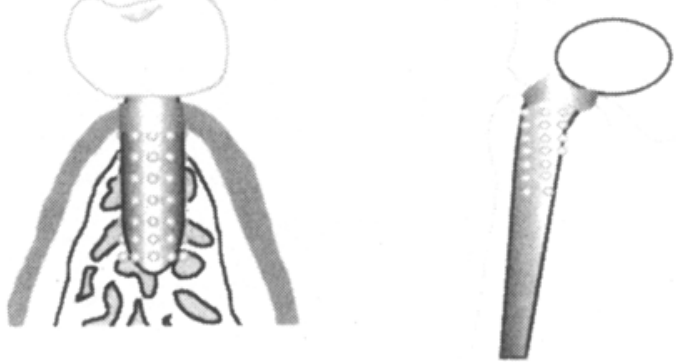

Figure 5. Application of HAp implanted superplastic titanium alloy. 
groups into the substrate materials as a means of stimulating calcium phosphate growth has been a technique often used by other researchers in the field for the purpose of stimulating apatite growth on various substrates. The surface modification by phosphorylation, giving surface sites, which have a crystallographic arrangement similar to that of hydroxyapatite, thereby allowing possible epitaxial growth (Dalas et al 1991) or by surface graft polymerization of a phosphoruscontaining monomer which induces the deposition of calcium and phosphate ions, in the form of a carbonated hydroxyapatite layer firmly bonded with the materials, has been employed (Tretinnikov et al 1994).

We studied a useful method for creating favourable local conditions which lead to the nucleation and growth of calcium phosphate on cellulose cotton fibre (Mucalo et al 1995a, b). This method of phosphorylation and partial hydrolysis of introduced phosphorous containing functionalities, by $\mathrm{Ca}(\mathrm{OH})_{2}$ treatment, resulted in hydrolysis products in intimate contact with the substance.

In this present study, chitin fibres were used as the substrate (instead of cellulose) on which to grow calcium phosphate, using a similar procedure (Yokogawa et al 1997). Chitin, a polymer of 2-acetamido-2-D-glucose, is
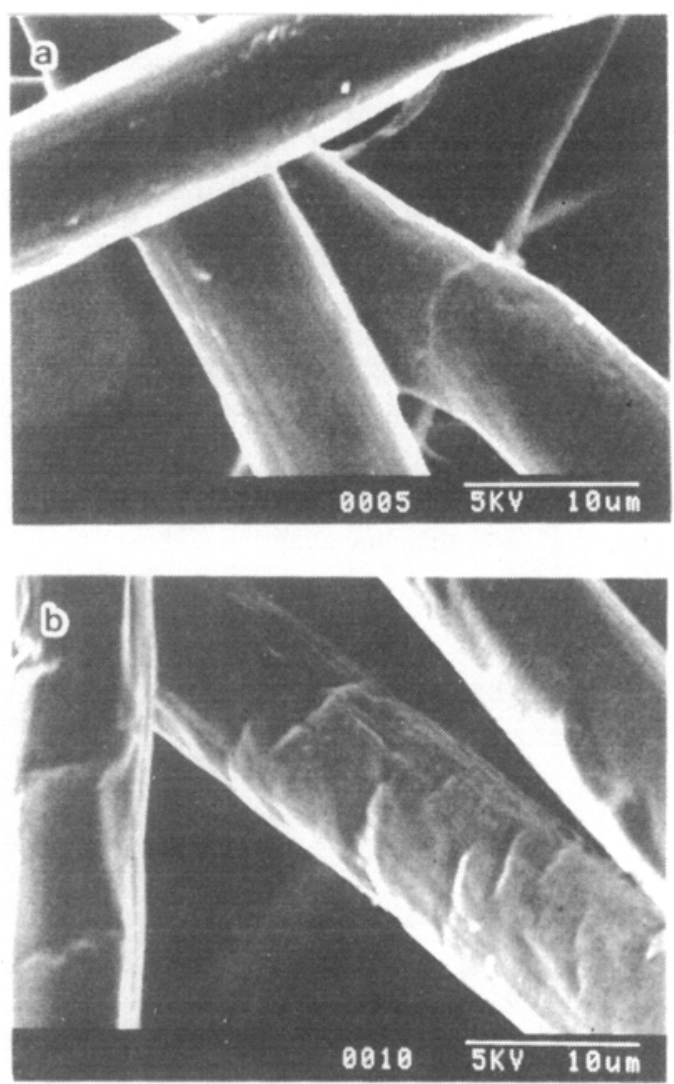

Figure 6. Scanning electron micrographs of (a) unphosphorylated chitin (as-received) fibres and (b) phosphorylated chitin fibres. the principal constituent of the shells of crabs, lobsters, and other crustaceans. It is also observed in the cell membranes of fungi and various bacteria. Chitin, very similar to cellulose in structure, also reacts in many ways similarly to cellulose, and is also biodegradable and non-toxic. The chitin/hydroxyapatite system has potential use as a virus filter, given the adsorptive properties of hydroxyapatite (Aoki 1994) which may allow the attachment of drugs for future treatment of serious viral diseases.

\subsection{Experimental}

Commercial chitin (Beschitin-W) was supplied by Unitika Ltd. The calcium phosphate growth medium used in all cases was $1.5 \times \mathrm{SBF}$ (simulated body fluid) solution. This solution is prepared by dissolving $\mathrm{NaCl}, \mathrm{KCl}, \mathrm{CaCl}_{2}$, $\mathrm{NaHCO}_{3}, \mathrm{~K}_{2} \mathrm{HPO}_{4}$, and $\mathrm{Na}_{2} \mathrm{SO}_{4}$ in distilled water together with Tris $\left[\left(\mathrm{CH}_{2} \mathrm{OH}\right)_{3} \mathrm{CNH}_{2}\right]$ and $\mathrm{HCl}$, which acted as buffering agents keeping the $\mathrm{pH}$ of the solution within the range of $7 \cdot 10-7.50$ during the soaking procedure.

The phosphorylation of the chitin samples was carried out by the following method. Twelve sheets $(1-2 \mathrm{~g})$ of chitin were placed in a round-bottomed flask equipped with a thermometer, mechanical stirrer, condenser, and $\mathrm{N}_{2}$ gas inlet tube. $40 \mathrm{~g}$ of urea was added to the flask along with $200 \mathrm{~mL}$ of dimethyl formamide (DMF). This solution was heated to a temperature of $110^{\circ} \mathrm{C}$ at which point a solution of $32 \mathrm{~g}$ of $98 \% \mathrm{H}_{3} \mathrm{PO}_{4}$ in $50 \mathrm{~mL}$ DMF was added. After further heating, the temperature of the reaction was increased to $155^{\circ} \mathrm{C}$ and left to reflux for $1 \mathrm{~h}$. At the end of the refluxing time, the reaction mixture was cooled under flowing $\mathrm{N}_{2}$ gas. The reaction solution was subsequently filtered off and the fibres were thoroughly washed in water to remove any excess phosphoric acid.

The phosphorylated chitin fibres were soaked in saturated $\mathrm{Ca}(\mathrm{OH})_{2}$ solution $(\mathrm{pH}=12.4)$ for 8 days. The

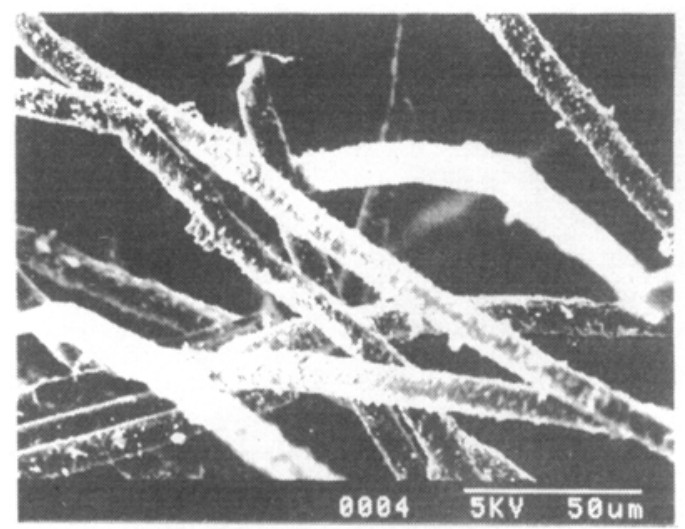

Figure 7. SEM of phosphorylated chitin fibres after soaking in $\mathrm{Ca}(\mathrm{OH})_{2}$ 
$\mathrm{Ca}(\mathrm{OH})_{2}$ solution was renewed every 4 days. After completion of the soaking period, the $\mathrm{Ca}(\mathrm{OH})_{2}$-treated phosphorylated chitin fibres were washed, filtered and dried under vacuum at $60^{\circ} \mathrm{C}$.

Samples $0.05-0.1 \mathrm{~g}$ of $\mathrm{Ca}(\mathrm{OH})_{2}$-treated phosphorylated chitin fibre were placed in a plastic screw-top flask to which $10-20 \mathrm{~mL}$ of $1.5 \times \mathrm{SBF}$ solution was added. The $\mathrm{pH}$ of the chitin $/ 1.5 \times \mathrm{SBF}$ solutions was then measured after the flasks were immersed in a covered water bath thermostatically controlled at $36 \cdot 5^{\circ} \mathrm{C}$ for periods of 1 , 2, 4, 6, 9, 10 and 17 days. For soaking periods of greater than one day, the $1.5 \times$ SBF solution was replaced each day and the $\mathrm{pH}$ of the old solution measured. After they were soaked for various periods, the chitin fibres were removed from the SBF solution, washed with distilled water, and then dried at $60^{\circ} \mathrm{C}$ under vacuum.

\subsection{Results and discussion}

Energy-dispersive X-ray spectrometry (EDXS) of the phosphorylated chitin fibres clearly showed that $P$ was present in the chitin fibres. The ICP-measured phosphorous content of the phosphorylated chitin was found to be at $2.95 \mathrm{wt} \%$ and lower than the phosphorus content
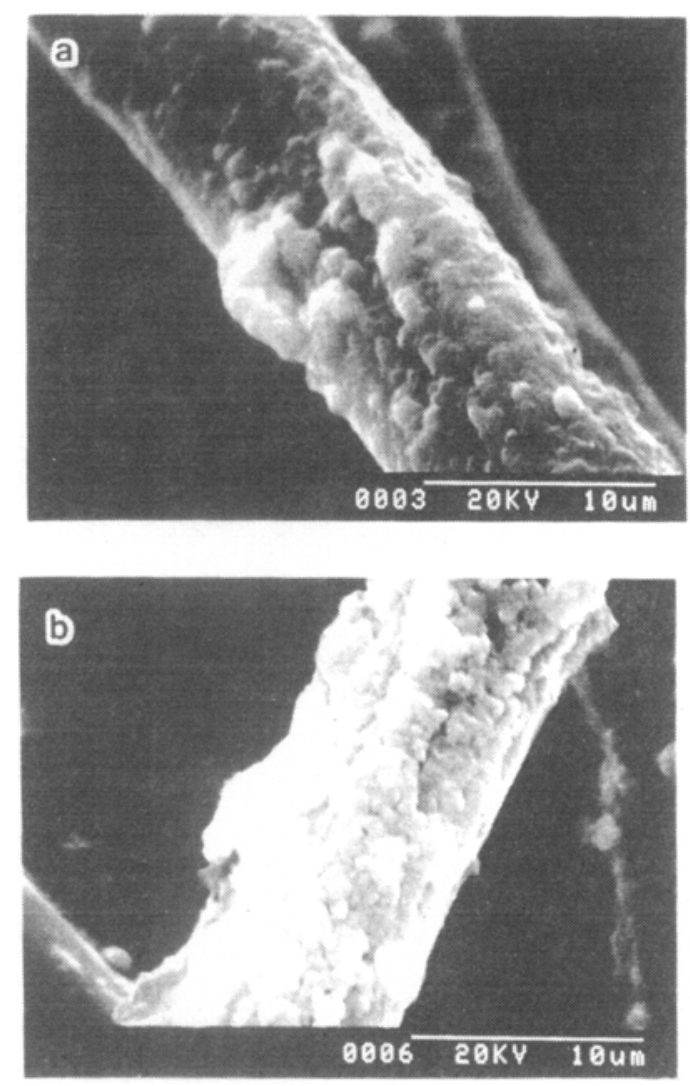

Figure 8. SEM of soaked chitin after phosphorylation and soaking in $\mathrm{Ca}(\mathrm{OH})_{2}$. (a) 6 days; (b) 10 days. of phosphorylated cellulose fibres (Mucalo et al 1995b). During phosphorylation, the chitin fibres may possibly decompose causing a decrease in the phosphorus content. During the reaction, the chitin fibres did not retain their original forms and showed a tendency to become loose in the gel. After drying, their form seemed to be restored and also appeared unchanged from that of the unphosphorylated chitin fibres (figure 6), but were somewhat weaker.

Phosphorylated chitin soaked in $\mathrm{Ca}(\mathrm{OH})_{2}$ solution appeared to be covered with a thin yet observable coating (figure 7). When EDXS analysis over a large area was carried out, a $\mathrm{Ca}: \mathrm{P}$ ratio of 1.78 was obtained, indicating a large amount of $\mathrm{Ca}$ in the sample which can be either attributed to $\mathrm{Ca}(\mathrm{OH})_{2}$ or $\mathrm{CaCO}_{3}$. High magnification EDXS analyses of the coated fibres gave a $\mathrm{Ca}: \mathrm{P}$ ratio of 1.29 . It has been speculated that at $\mathrm{pH}>6.3$, octacalcium phosphate (OCP) is the preferred precursor for supersaturation in solutions containing $\mathrm{Ca}^{2+}$ and $\mathrm{HPO}_{4}^{2-}$ ions. It is assumed that $\mathrm{Ca}(\mathrm{OH})_{2}$ partially hydrolyzed the chitin- $\mathrm{PO}_{4}$ groups to produce perhaps OCP as an initial phase that is then rapidly transformed into calcium-deficient apatite. In contrast, phosphorylated chitin fibres not subjected to the $\mathrm{Ca}(\mathrm{OH})_{2}$ treatment did not exhibit calcium phosphate growth upon immersion in $1.5 \times$ SBF solution.

Figure 8 shows $\mathrm{SEM}$ photos of the $\mathrm{Ca}(\mathrm{OH})_{2}$-treated phosphorylated chitin surface after immersion in $1.5 \times \mathrm{SBF}$ solution as a function of soaking time in days. Soaking of the $\mathrm{Ca}(\mathrm{OH})_{2}$-treated phosphorylated chitin fibres in $1.5 \times \mathrm{SBF}$ solution was found to lead to the deposition of a calcium phosphate layer. It is believed that the thin coatings of calcium phosphate material on the fibres, produced by partial hydrolysis of the chitin $\mathrm{PO}_{4}$ functionalities during soaking in saturated $\mathrm{Ca}(\mathrm{OH})_{2}$ solution, act as a nucleation layer upon which the calcium

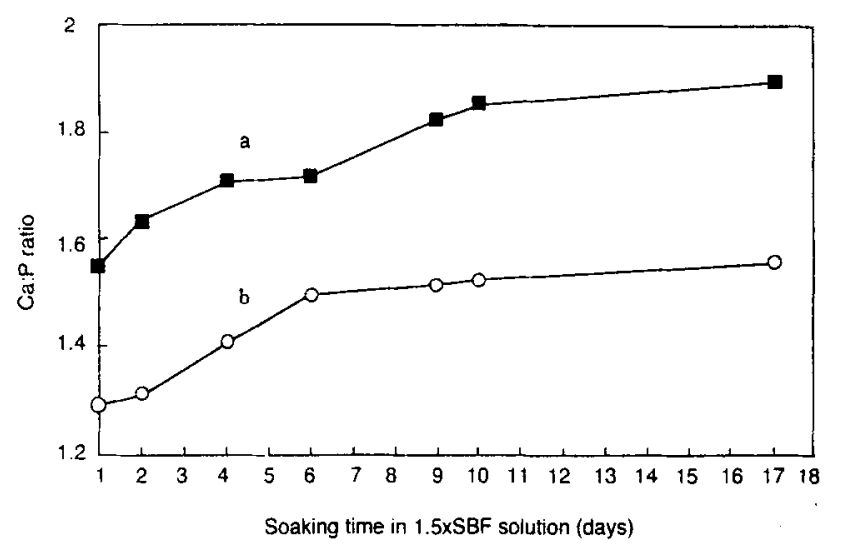

Figure 9. $\mathrm{Ca}: \mathrm{P}$ ratios of calcium phosphate coatings soaked in $\mathrm{Ca}(\mathrm{OH})_{2}$ and $1.5 \times \mathrm{SBF}$ solution at $36.5^{\circ} \mathrm{C}$. (a) $\mathrm{Ca}: \mathrm{P}$ ratios over a large area; and (b) $\mathrm{Ca}: \mathrm{P}$ ratios measured for individual coating at high magnification. 
phosphate can grow from the $1.5 \times \mathrm{SBF}$ solution. In general, the growth of calcium phosphate from $1.5 \times \mathrm{SBF}$ solution begins immediately after 1 day of soaking. This suggests that clusters have partially dissolved upon introduction of chitin into the $1.5 \times \mathrm{SBF}$ solution. The growth of the calcium phosphate layer, after soaking for 1-6 days, appears to proceed by nucleation on the existing coating in the form of circular flakes which then grow in number and size on the surface. After soaking for 9-17 days, a thicker coating was observed.

Figure 9 illustrates the EDXS-measured $\mathrm{Ca}: \mathrm{P}$ ratio for the calcium phosphate coating as a function of soaking time in $1.5 \times \mathrm{SBF}$ solution. Curve (a) shows that the sample has higher $\mathrm{Ca}: \mathrm{P}$ ratio over a large area, which suggests Ca-enrichment due to the presence of calcium carbonate or calcium hydroxide. Curve (b), however, should be interpreted as the characteristic $\mathrm{Ca}: \mathrm{P}$ ratios of the actual coatings deposited on individual fibres, ranging from 1.29 to 1.55 , suggesting Ca-deficient apatite.

\subsection{Conclusions}

Calcium phosphate growth on phosphorylated chitin fibres was studied. Chitin fibres were phosphorylated using urea and $\mathrm{H}_{3} \mathrm{PO}_{4}$ and then soaked in saturated $\mathrm{Ca}(\mathrm{OH})_{2}$ solution at ambient temperature, which led to the formation of thin coatings formed by partial hydrolysis of $\mathrm{PO}_{4}$ functionalities, were found to stimulate the growth of a calcium phosphate coating on their surfaces after soaking in $1.5 \times$ SBF solution for as little as 1 day. The thin layer after $\mathrm{Ca}(\mathrm{OH})_{2}$ treatment functioned as a nucleation layer for further calcium phosphate deposition after soaking in $1.5 \times \mathrm{SBF}$ solution.

\section{Future of hybrid bioceramics}

It is feasible to use hybrid bioceramics of HAp-implanted superplastic titanium alloy in hard biological tissues without replacement forever. HAp-coated polymers of cellulose and chitin have large potentiality in use as a virus filter, artificial trachea and bone-like materials.

\section{References}

Aoki H 1994 Medical applications of hydroxyapatite (Tokyo, St. Louis: Shiyaku Euroamerica Inc.) p. 144

Dalas E, Kailitsis J K and Koutsoukos P G 1991 Langmuir 7 1822

Geesink R G T, Groot K and Kllein C P A T 1987 Clin. Orthop. Relat. Res. 225147

Hanawa T, Ukai H and Murayama K 1993 J. Electron Spectrosc. Relat. Phenom. 631347

Mucalo M R, Yokogawa Y, Toriyama M, Suzuki T, Kawamoto Y, Nagata F and Nishizawa K 1995a J. Mater. Sci. Mater. Med. 6597

Mucalo M R, Yokogawa Y, Suzuki T, Kawamoto Y, Nagata F and Nishizawa K 1995b J. Mater. Sci. Mater. Med. 6658

Nonami T, Kamiya A, Naganuma K and Kameyama T $1998 \mathrm{~J}$. Mater. Sci. Mater. Med. 9203

Ohgaki M and Aoki H 1993 Chem. Ind. Dev. 44693

Ouchi C, Nikawa K, Takahashi K and Ogawa A 1992 NKK Gihou 13817

Tretinnikov O N, Kato K and Ikada Y 1994 J. Biomed. Mater. Res. 281365

Yokogawa Y et al 1997 J. Mater. Sci. Mater. Med. 8407 